\title{
Intranasal insulin reverts central pathology and cognitive impairment in diabetic mother offspring
}

\author{
Juan Jose Ramos-Rodriguez ${ }^{1,2}$, Daniel Sanchez-Sotano 1,2,3, Alberto Doblas-Marquez ${ }^{1,2}$, Carmen Infante-Garcia ${ }^{1,2}$, \\ Simon Lubian-Lopez ${ }^{4}$ and Monica Garcia-Alloza ${ }^{1,2^{*}}$
}

\begin{abstract}
Background: Adverse effects in diabetic mothers offspring (DMO) are a major concern of increasing incidence. Among these, chronic central complications in DMO remain poorly understood, and in extreme cases, diabetes can essentially function as a gestational brain insult. Nevertheless, therapeutic alternatives for DMO are limited.

Methods: Therefore, we have analyzed the central long-term complications in the offspring from CD1 diabetic mothers treated with streptozotozin, as well as the possible reversion of these alterations by insulin administration to neonates. Brain atrophy, neuronal morphology, tau phosphorylation, proliferation and neurogenesis were assessed in the short term (P7) and in the early adulthood (10 weeks) and cognitive function was also analyzed in the long-term.

Results: Central complications in DMO were still detected in the adulthood, including cortical and hippocampal thinning due to synaptic loss and neuronal simplification, increased tau hyperphosphorylation, and diminished cell proliferation and neurogenesis. Additionally, maternal diabetes increased the long-term susceptibility to spontaneous central bleeding, inflammation and cognition impairment in the offspring. On the other hand, intracerebroventricular insulin administration to neonates significantly reduced observed alterations. Moreover, non-invasive intranasal insulin reversed central atrophy and tau hyperphosphorylation, and rescued central proliferation and neurogenesis. Vascular damage, inflammation and cognitive alterations were also comparable to their counterparts born to nondiabetic mice, supporting the utility of this pathway to access the central nervous system.

Conclusions: Our data underlie the long-term effects of central complications in DMO. Moreover, observed improvement after insulin treatment opens the door to therapeutic alternatives for children who are exposed to poorly controlled gestational diabetes, and who may benefit from more individualized treatments.
\end{abstract}

Keywords: Diabetes, Offspring, Insulin, Tau, Haemorrhage, Inflammation

\section{Background}

Gestational diabetes affects $3-10 \%$ of pregnant women [1] and epidemiological and animal studies have previously shown that the risk of adverse maternal and perinatal outcomes continuously increases with maternal glycaemia [2]. Following this idea, malformation and mortality rates are reportedly two to five fold higher in diabetic mothers offspring (DMO) (for review [3]). Moreover, these foetal

\footnotetext{
* Correspondence: monica.garcia@uca.es

'Division of Physiology, School of Medicine Universidad de Cadiz, Plaza

Fragela sn, 4 piso 410, Cadiz, Spain

${ }^{2}$ Instituto de Investigación Biomédica e Innovación en Ciencias Biomédicas

de la Provincia de Cádiz (INiBICA), Cadiz, Spain

Full list of author information is available at the end of the article
}

and neonatal complications seem to continue at later stages and have been largely studied at metabolic level [4]. Central nervous system (CNS) complications in DMO are also receiving attention in recent years and many studies have focused on hypothalamic alterations in relation with future metabolic disorders [5, 6]. Prolonged hyperglycaemia during critical periods of development underlie malformations in the foetal brain [7] and insulin is also an important regulator of developmental and cognitive functions in the CNS [8]. Optimal control of glucose levels during pregnancy is highly pursued, however, short and long-term related complications are still present and in extreme cases, diabetes has been suggested to essentially 
function as a gestational brain insult [9] resulting in behavioural problems, language impairment or cognitive development deficits $[9,10]$. However, to our knowledge exhaustive chronic evaluation of the CNS has not been performed, and the study of therapeutic options should also be addressed. Therefore, we have assessed short and long-term metabolic and central complications in DMO. Moreover, we have attempted to reverse observed alterations by treating DMO with insulin. Although previous studies have treated diabetic mothers with insulin to counterbalance disturbances in the offspring, to our knowledge no preceding studies have directly administered intracerebroventricular (ICV) or intranasal (IN) insulin to DMO. In our hands, DMO presented metabolic alterations in the adulthood, including modified glucose and insulin levels in glucose tolerance tests, while insulin administration significantly improved this aspect. When we analyzed the CNS, DMO presented long-term cortical and hippocampal thinning due to neuronal simplification and synaptic loss, accompanied by reduced central proliferation and neurogenesis, while insulin treatments reverted these effects. Also, spontaneous central bleeding in DMO was significantly improved after insulin administration, and markers of neuronal damage, such as tau hyperphosphorylation were controlled by insulin. Cognition impairment was significantly reversed after insulin treatment. An overall improvement was observed after both, IN and ICV insulin administration, nevertheless, IN pathway lead to a more robust recovery, supporting the utility of this approach to guarantee insulin access to the CNS. Altogether our data could help to elucidate the underlying central complications in DMO and open the door to therapeutic alternatives for children who are exposed to poorly controlled gestational diabetes.

\section{Methods}

\section{Animals and treatments}

Two months old CD1 breeders were treated with streptozotozin (STZ) $(50 \mathrm{mg} / \mathrm{Kg})$ for 5 consecutive days [11] prior crossing with healthy males. Both female and male offspring from diabetic and control mothers were randomly divided and sacrified immediately after birth or at P7. A set of animals received unilateral ICV insulin (ICV-Ins) injection at P7 [12, 13]. Briefly, mice were anesthetized with isoflurane (Astrazeneca, Spain) and placed in a sterotaxic device (David-Kopf Instruments, Tujunga, CA, USA). ICV administration consisted of $1 \mu \mathrm{l}$ of insulin (5 mIU) in PBS, at the following coordinates: $\mathrm{AP}-3 \mathrm{~mm}, \mathrm{ML}-1 \mathrm{~mm}$ y $\mathrm{DV}+4 \mathrm{~mm}$ from Bregma. Injections were performed with a $5 \mu$ l Hamilton syringe (Hamilton Company, Bonaduz, Switzerland) at a constant flow rate of $0.2 \mu \mathrm{l} / \mathrm{min}$ for $5 \mathrm{~min}$. A delay of 5 min was allowed before complete retraction of the needle to minimize aspiration of the toxin. Sham operated mice followed the same procedure but only PBS was injected. A second group received IN insulin (IN-Ins), for 7 consecutive days (P7-P13) as previously described [14, 15]. Briefly, mice received $1 \mathrm{IU} /$ day of insulin in PBS. Mice were lightly anesthetized with isoflurane and held gently on their backs. A $10 \mu \mathrm{l}$ pipette was used for intranasal administration ( $1.25 \mu \mathrm{l}$ of insulin every minute) alternating nostrils. Insulin drops were placed in the opening of the nostril, allowing the mouse to snort each drop into the nasal cavity. A total of $5 \mu \mathrm{l}$ of insulin were delivered over a course of 4 min. Control mice received PBS following a similar approach. Long-term effects of the ICV-Ins and IN-Ins treatments was assessed at 10 weeks of age. For proliferation and neurogenesis studies animals received BrdU ip $(70 \mathrm{mg} /$ $\mathrm{Kg}$ ) for 3 consecutive days immediately before sacrifice.

DMO were assigned to foster mothers immediately after birth to guarantee regular postnatal feeding and development. Groups and treatments are presented in Fig. 1g. Metabolic and postmortem characterization included 4-6 animals per group at P1 and 4-7 mice per group at P7. Five weeks old assessment included 5-15 mice and 10 weeks old studies included 6-28 mice per group for behavioural and metabolic assessment and 3-10 mice per group in postmortem studies. Individual sample size for each experiment is detailed in figure legends. In order to guarantee the access of insulin to the brain, a set of animals $(n=3-4)$ was treated with ICV-Ins or INIns, as described above, and scarified to measure brain insulin levels in the olfactory bulb, cortex, hippocampus and striatum. All experimental procedures were approved by Junta de Andalucia, (Guidelines for Care and Use of Experimental Animals, European Commission Directive 2010/63/UE and Spanish Royal Decree 53/2013).

\section{Brain insulin levels}

Brain insulin levels were measured in the olfactory bulb, cortex, hippocampus and striatum of a set of mice, after ICV-Ins and IN-Ins, to guarantee the access to the brain after both administration pathways. Briefly, animals received an overdose of pentobarbital $(60 \mathrm{mg} / \mathrm{Kg})$ (Sigma, St. Louis, MO, USA Sigma MO). Selected brain regions were harvested and snap frozen until used. Tissue was homogenised in lysis buffer (CellSignaling, USA) supplemented with a protease inhibitor cocktail (Sigma, USA) and insulin levels were determined by human enzymelinked immunosorbent assay (Mercodia, Spain Iso-Insulin ELISA 10-1128-01).

\section{Metabolic characterization}

Body weight was determined in the mothers before STZ administration and on the day of birth, and weight gain was calculated. Postprandial glucose levels were measured before STZ treatment, one week after STZ administration, after crossing and the day of birth. Insulin 


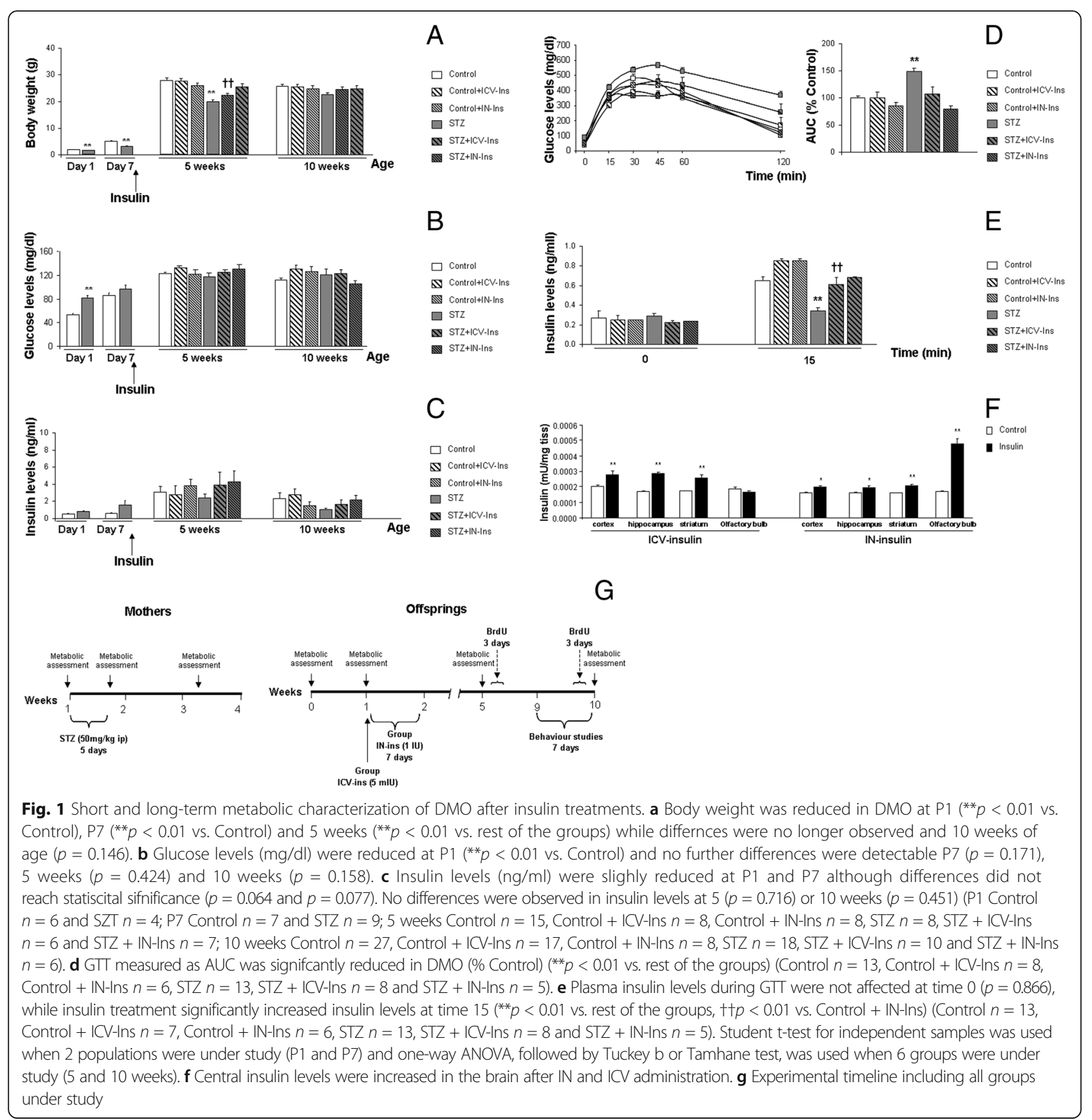

levels were also measured immediately before STZ administration and the day of birth. Body weight, glucose levels and insulin levels were determined in all offspring (both male and female) the day of birth, and on P7. Endpoint experiments were programmed to determine glucose and insulin levels due to the volume of blood required. Briefly, animals were deeply anesthetized with pentobarbital $(60 \mathrm{mg} / \mathrm{kg})$ and blood was withdrawn by cardiac puncture. Glucose an insulin levels were also determined after ICV-Ins or IN-Ins administration, at 5 and 10 weeks of age. Additionally, at 10 weeks of age, before sacrifice, intraperitoneal glucose tolerance test (GTT) ( $2 \mathrm{~g} / \mathrm{Kg}$ body weight, Sigma, OR; USA) was performed [16]. Blood glucose levels were measured in $\mathrm{mg} / \mathrm{dl}$ using the glucometer Optium Xceed (Abbott, United Kingdom). Plasma insulin levels were measured in $\mathrm{ng} / \mathrm{ml}$ using ultrasensitive mouse enzyme-linked immunosorbent assay (Mercodia, Spain Mouse Insulin ELISA 10-1247-01).

Motor activity and new object discrimination (NOD) task Seven days prior to sacrifice we assessed spontaneous locomotor activity in male and female offspring, 
measuring the distance travelled by mice for $30 \mathrm{~min}$ on day 1 , before the commencement of the NOD test. Integrated episodic memory for "what", "where" and "when" paradigms were analyzed as previously described [17].

\section{Morris water maze (MWM)}

Spatial cognition assessment commenced in the same mice the day after concluding the NOD test. Acquisition consisted in 4 trials/day (60 $\mathrm{s} /$ trial) for 4 days, with the platform submerged in quadrant 2 . If the animal did not find the platform it was placed on it for $10 \mathrm{~s}$. Retention started a day after and consisted in a single trial with the platform removed [17]. Time required to locate the platform in the acquisition phase, percentage of time spent in quadrant 2 during the retention phase and swim speed were analyzed using Smart software, (Panlab, Spain).

\section{Tissue processing}

Cortex and hippocampus from the right hemisphere, from both male and female offspring, were dissected and snap frozen for cresyl violet, Prussian blue, caspase activity and western blot studies. Left hemispheres, from both male and female offspring, were fixed in paraformaldehyde for 2 weeks before $30 \mu \mathrm{m}$ coronal sections were obtained. In case of ICV treated mice, only ipsilateral hemispheres were used and brains from males and females were either dissected or snap frozen. Similarly, P1 and P7 tissue was snap frozen for biochemical determinations.

\section{Cresyl violet and Prussian blue staining}

Brain morphology was analyzed after cresyl violet staining in sections (1.5 to $-3.5 \mathrm{~mm}$ from Bregma). Cortex and hippocampus thickness were measured using Adobe Photoshop and Image J software as previously described [18].

Presence of haemorrhages was conducted using Prussian blue iron staining and neutral red counterstain in consecutive sections. Sections were imaged with an Olympus Bx60 microscope (Japan) and an Olympus DP71 camera. Images were analyzed using Adobe PhotoShop and Image J softwares to quantify number of haemorrhages, individual haemorrhage size, and haemorrhage burden in the cortex and hippocampus [18].

\section{Caspase activation}

Caspases 3/7 activity was analyzed in cortical homogenates from all groups in this study using the Caspase-Glo 3/7 assay (Promega, Madrid, Spain), following manufacturer's indications, as previously described [19].
Inmunohistochemistry studies: 5-bromo-3-deoxyuridin, doublecortin, NeuN and microglia

5-bromo-3-deoxyuridine (BrdU) and doublecortin (DCX) immunohistochemistry was performed in the cortex, hippocampus and the subventricular zone (SVZ) (0.5, and $0.0 \mathrm{~mm}$ from Bregma). Anti-BrdU 1:100 (Dako, Barcelona, Spain) and anti-DCX 1:400 (SantaCruz Biotechnology, Santa Cruz, CA, USA) were used as primary antibodies and Alexa Fluor 594 and Alexa Fluor 488 (1:100) (Invitrogen, Carlsbad, CA, USA) as secondary antibodies [18]. DCX burden (percentage of area covered by DCX-positive cells) was quantified in the SVZ [18] and number of individual DCX-and BrdU-positive cells were quantified in the cortex and hippocampus using Image J software.

NeuN and microglia immunohistochemistry was performed as described [20]. Anti-Iba1 (Wako, Osaka,Japan) (1:2000) or anti-NeuN (Chemicon, CA, USA) (1:200) (Invitrogen, Carlsbad, CA, USA) were used as primary antibodies and Alexa Fluor 488 and Alexa Fluor 594 (1:200) as secondary antibodies. DAPI $1 \mathrm{mg} / \mathrm{ml}$ (Sigma) (1:2000) counterstain was used. The percentage of NeuNpositive cells (normalized by total cells stained with DAPI) was quantified as previously described [21]. Number of microglia cells, individual microglia size and burden were quantified in the cortex and hippocampus using Image software [20].

\section{Golgi-Cox staining}

Neuronal complexity was measured by Golgi-Cox staining, using Rapid Golgi Stain Kit (FD Neurotechnologies, USA. Ref: PK401). Kit instructions were followed as previously described [20] in all of our animals (both male and female). Neuronal complexity was analyzed by sholl analysis in $10 \mu \mathrm{m}$ concentric circles from neuronal soma. Spine density was calculated (spines/10 $\mu \mathrm{m}$ ) [20]. Ratios of curvature were calculated by dividing the end-to-end distance of a dendrite segment by the total length between the two segment ends. Analysis was completed using Image J software, as previously described [22].

\section{Western blot for tau, Akt and synaptophysin}

Tau, tau phosphorylation, Akt and phospho-Akt were measured in cortical and hippocampal samples as previously described [23] at P1, P7 and 10 weeks. To prove insulin central effects early Phospho-Akt/total Akt ratios are were also measured in a set of offspring $4 \mathrm{~h}$ after ICV or last intranasal insulin administration. Phosphotau clone AT8 (1:1000, Fisher Scientific, MA, USA), phospho-Akt (Ser473) (1:1000) (Cell signaling, USA), anti-synaptophysin (1:1000) (Zymed, USA), anti-total Akt antibody (1:1000) (cell signaling, USA) and anti-total tau antibody (1:1000) (DAKO, Denmark) were used. Optical density was semi-quantified after normalizing to $\beta$-actin (1:2,500,000) (Sigma, USA), using Image J 
software. Phospho-tau/total tau, phospho-Akt/total Akt ratios and synaptophysin levels were represented as percentage of Control values.

\section{Statistical analysis}

Student $\mathrm{t}$ test for independent samples or one-way ANOVA, followed by Tuckey b test or Tamhane tests as required, were used. Two-way ANOVA (groupXday) was used to analyze the the MWM test. SPSS v.15 software was used for all statistical analysis.

\section{Results}

\section{Metabolic characterization}

No differences were detected among mothers before STZ treatment when body weight $(p=0.850)$, glucose levels $(p=0.798)$ or insulin levels were compared $(p=0.382)$ (Table 1). We detected a significant increase of glycaemia one week after STZ treatment $(* * p=0.005$ vs. Control). At the date of birth body weight was significantly lower in STZ-treated mothers ${ }^{* * *} p=0.003$ vs. Control) and the increase of body weight was also significantly compromised (** $p=0.003$ vs. Control). The day of birth insulin levels were lower in STZ-treated mothers $(* * p=0.005$ vs. Control) and glucose levels were highly increased (*** $p<0.001$ vs. Control) (Table 1$)$.

In DMO, body weight was reduced at P1 $(* * k<0.01$ vs. Control) and P7 ( ${ }^{* * *} p<0.01$ vs. Control) (Fig. 1a). Glucose levels $(\mathrm{mg} / \mathrm{dl})$ were slightly higher in DMO at P1 ${ }^{* * *} p<0.01$ vs. Control), and this effect recovered by day $7(p=0.171)$ (Fig. 1b). Slight reductions of insulin levels $(\mathrm{ng} / \mathrm{ml})$ in DMO did not reach statistical significance at P1 $(p=0.064)$ or P7 $(p=0.077)$ (Fig. 1c). By

Table 1 Metabolic assessment of STZ-treated mothers

\begin{tabular}{lll}
\hline & \multicolumn{2}{l}{ Treatment } \\
\cline { 2 - 3 } & Control & STZ \\
\hline Initial body weight $(\mathrm{g})$ & $30.72 \pm 1.06$ & $31.11 \pm 1.45$ \\
Body weight $(\mathrm{g})$ at birth & $42.31 \pm 1.31$ & $35.76 \pm 1.09^{* *}$ \\
Increase in body weight (g) & $11.6 \pm 1.45$ & $5.43 \pm 0.85^{* *}$ \\
Initial insulin levels (ng/ml) & $0.63 \pm 0.17$ & $0.94 \pm 0.24$ \\
Insulin levels (ng/dl) at birth & $0.44 \pm 0.14$ & $0.03 \pm 0.01$ \\
Initial glucose levels (mg/dl) & $111.20 \pm 5.08$ & $112.75 \pm 3.46$ \\
Glucose levels (mg/dl) & $100.60 \pm 10.54$ & $184.38 \pm 17.67^{* *}$ \\
before crossing & & \\
Glucose levels (mg/dl) & $111.40 \pm 8.90$ & $487.27 \pm 44.27^{* *}$ \\
after crossing & & \\
Glucose levels (mg/dl) at birth & $94.00 \pm 3.05$ & $500.38 \pm 39.29^{* *}$ \\
\hline
\end{tabular}

Initial body weight $(p=0.850)$, glucose levels $(p=0.798)$ or insulin levels $(p=0.382)$ were similar in both groups before STZ administration. Glucose levels immediately before crossing (one week after commencement of the treatment) were increased in STZ treated mice ${ }^{* *} p=0.005$ vs. Control). The date of birth, body weight $\left({ }^{* *} p=0.003\right.$ vs. Control) and the increase of body weight $\left({ }^{* *} p=0.003\right.$ vs. Control) were significantly lower in STZ-treated mothers. The day of birth insulin levels were lower in STZ-treated animals (** $p=0.005$ vs. Control) while glucose levels were increased after crossing and at birth $\left(^{* *} p<0.001\right.$ vs. Control)
5 weeks of age DMO body weight was still lower than the rest of the groups, and while ICV-Ins treatment significantly reduced this effect, only IN-Ins completely reversed the situation $\left[\mathrm{F}_{(5,43)}=8.48,{ }^{* * *} p<0.01\right.$ vs. rest of the groups] (Fig. 1a). By 10 weeks of age differences in body weight were no longer detectable $\left[\mathrm{F}_{(5,79)}=1.16\right.$, $p=0.146$ ] (Fig. 1a). Insulin levels were slightly lower in DMO by 5 and 10 weeks, although differences did not reach statistical significance and central insulin treatments did not have a significant effect on peripheral insulin levels (Fig. 1c). No differences were detected in glucose levels at 5 or 10 weeks after birth in DMO $\left(\left[\mathrm{F}_{(5,46)}=0.579, p=0.716\right]\right.$ and $\left[\mathrm{F}_{(5,79)}=0.955\right.$, $p=0.451]$ respectively) (Fig. 1b). However, GTT in 10 weeks old mice revealed altered glucose tolerance in DMO, while a complete recovery was observed after insulin treatments $\left[\mathrm{F}_{(3,45)}=12.29,{ }^{* *} p<0.01\right.$ vs. rest of the groups] (Fig. 1d). Plasma insulin levels during GTT were significantly lower in $\mathrm{DMO}$ and insulin treatments corrected this effect $\left[\mathrm{F}_{(5,47)}=10.32,{ }^{* *} p<0.01\right.$ vs. rest of the groups, $+\uparrow p<0.01$ vs. Control + IN-Ins] (Fig. 1e).

Insulin levels in the brain were also tested after IN and ICV delivery. An overall increase of central insulin levels was observed in all regions under study. As it could be expected, higher insulin levels were observed in the olfactory bulb after in intranasal administration, while insulin levels were higher in the hippocampus and the striatum after ICV administration (Fig. 1f).

\section{Cognitive assessment}

By 10 weeks, of age episodic memory was significantly impaired in DMO for all three paradigms under study: "what", "where" and "when". ICV-Ins recovered "what" and "where" limitations while IN-Ins completely reversed all three paradigms ("What" $\left[\mathrm{F}_{(5,252)}=48.55\right.$, *** $p<0.01$ vs. rest of the groups, $\neq \neq p<0.01$ vs Control, Control + IN-Ins, STZ + ICV-Ins, STZ + IN-Ins, $++p<0.01$ vs. Control + IN-Ins and STZ + IN-Ins]. "Where" $\left[\mathrm{F}_{(5,249)}=34.21\right.$, "** $p=0.001$ vs. rest of the groups]. "When" $\left[\mathrm{F}_{(5,245)}=4.49,+\dagger p=0.001\right.$ vs. Control + IN-Ins and STZ + IN-Ins] (Fig. 2a). A similar outcome was observed in the MWM test. The acquisition showed a significant treatmentXday effect $\left[\mathrm{F}_{(15,1263)}=2.705,{ }^{* *} p<0.01\right]$. Further assessment of individual days revealed an overall improvement in insulin treated mice. This effect was specially relevant in IN treated mice: day $1\left[\mathrm{~F}_{(5335)}=2.994, \# p=0.012\right.$ vs. Control + IN-Ins $]$, day $2\left[\mathrm{~F}_{(5325)}=18.23,{ }^{* *} p<0.01\right.$ vs. rest of the groups, $++p<0.01$ vs. Control + IN-Ins and STZ + IN-Ins $]$, day $3\left[\mathrm{~F}_{(5332)}=18.90\right.$, , $\neq \neq p<0.01$ vs. Control + IN-Ins and STZ + IN-Ins, Control and Control + ICV-Ins groups, $+\dagger p<0.01$ vs. Control $+\mathrm{IN}-$ Ins and STZ + IN-Ins $]$, day $4\left[\mathrm{~F}_{(5330)}=23.676,{ }^{* * *} p<0.01\right.$ vs. rest of the groups, $+\dagger p<0.01$ vs. Control + IN-Ins and 


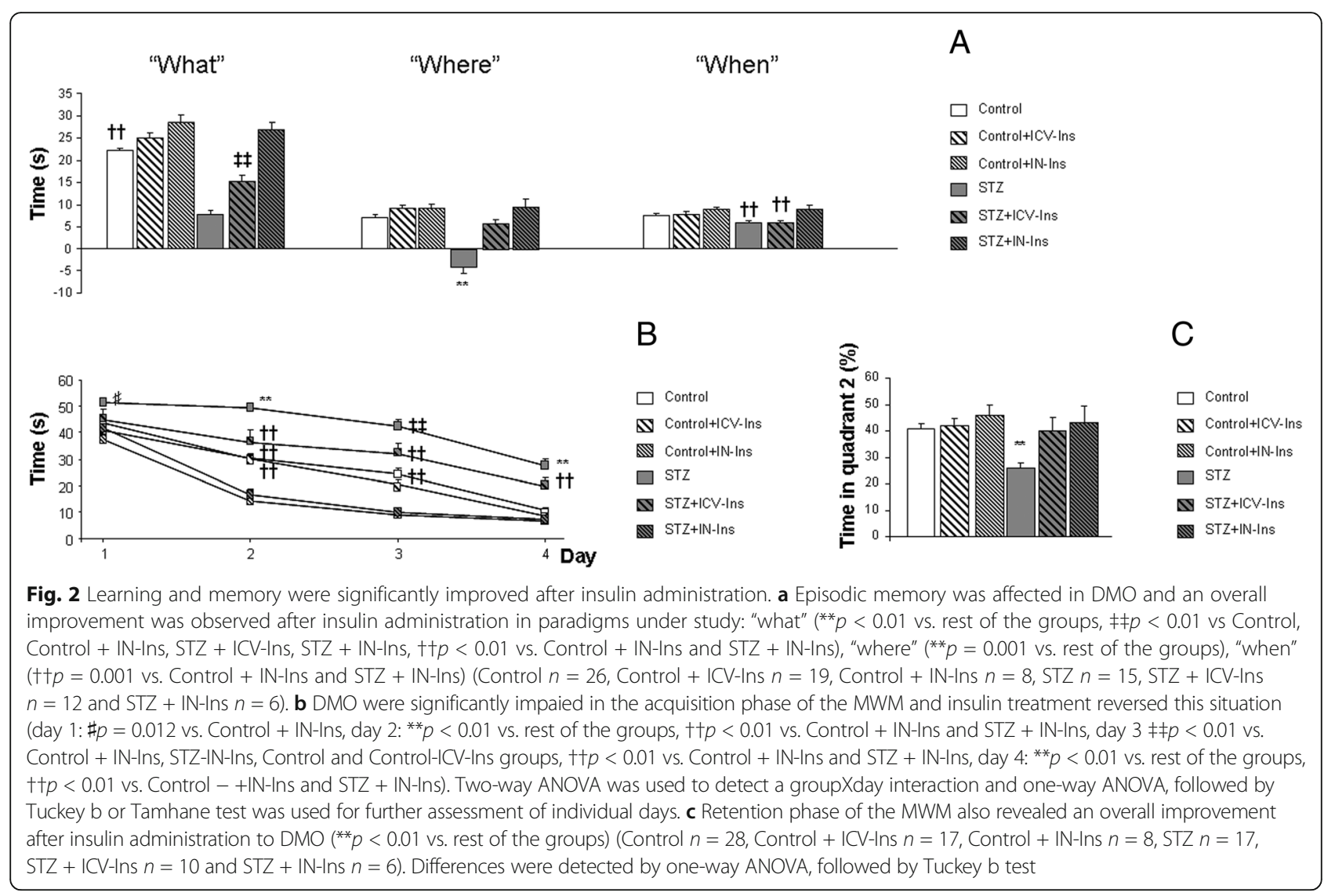

STZ + IN-Ins] (Fig. 2c). On the $24 \mathrm{~h}$ retention phase memory was significantly impaired, and improved after IN or ICV-Ins administration $\left[\mathrm{F}_{(5,73)}=5.42,{ }^{* * *} p<0.01\right.$ vs. rest of the groups] (Fig. 2d).

\section{Central atrophy, neuronal and synaptic alterations}

Brain weight was reduced in P1 DMO (*** $p<0.01$ vs. Control) and P7 (*** $p<0.01$ vs. Control) (Fig. 3a). At 10 weeks of age a partial recovery was observed in STZ + IN-Ins and STZ + ICV-Ins treated mice $\left[\mathrm{F}_{(5,75)}=33.084{ }^{* * *} p<0.01\right.$ vs. rest of the groups, $+\dagger p<0.01$ vs. Control and Control + ICV-Ins] (Fig. 3a). Cortical thickness was reduced in DMO, while insulin treatments counterbalanced this effect $\left[\mathrm{F}_{(5165)}=3.68\right.$, $* p=0.03$ vs. rest of the groups] (Fig. 3b and c). A similar profile was observed in the hippocampus $\left[\mathrm{F}_{(5,73)}=5.32 * p<0.01\right.$ vs. rest of the groups] (Fig. 3b). Caspase activation assay, as a marker of cell death, was significantly increased in the cortex from DMO at P1 ${ }^{(* * *} p<0.01$ vs. Control) and P7 (" $p=0.016$ vs. Control) while differences were no longer observed at 10 weeks of age $\left[F_{(5,24)}=2.33, p=0.074\right]$. A similar profile was observed in the hippocampus at P1 $\left({ }^{*} p=0.014\right.$ vs. Control) or P7 (*** $p=0.005$ vs. Control) (Fig. 3d).

NeuN-positive cells/total cells ratio was reduced in DMO, improved by ICV-Ins administration, and returned to control levels after IN-Ins treatment $\left[\mathrm{F}_{(5,3435)}=75.81,{ }^{* * *} p<0.01\right.$ vs. rest of the groups, $++p<0.01$ vs. Control, Control + ICV-Ins, Control + INIns and STZ + IN-Ins] (Fig. 3e and f). While neurite curvature was not affected $\left[\mathrm{F}_{(5,1062)}=0.649\right]$ (Fig. 3g) spines density was reduced in $\mathrm{DMO}$, and it recovered after insulin administration $\left(\left[\mathrm{F}_{(5473)}=17.32, * * p<0.01\right.\right.$ vs. rest of the groups, $\neq \neq p<0.01$. vs. Control + IN-Ins and STZ + IN-Ins]) (Fig. 3f and j). Also, neurite simplification in $\mathrm{DMO}$, recovered in insulin treated animals. Analysis of intersections by sholl analysis revealed a groupXradius distance effect $\left[\mathrm{F}_{(25,3130)}=3.38, p<0.01\right]$. Further analysis in $10 \mu \mathrm{m}$ steps revealed a reduction of dendrite branching in DMO that was increased after ICV-Ins and improved after IN-Ins treatment: $<10 \mu \mathrm{m}\left[\mathrm{F}_{(5532)}=39.69,++p<0.01\right.$ vs. Control, Control + ICV-Ins, Control + IN-Ins, $\mathrm{STZ}+\mathrm{IN}-$ Ins, $\neq \neq p<0.01$. vs. Control + IN-Ins and $\mathrm{STZ}+\mathrm{IN}-\mathrm{Ins}], 10-20 \mu \mathrm{m}\left[\mathrm{F}_{(5523)}=58.05,{ }^{* * *} p<0.01\right.$ vs. rest of the groups, $\neq \neq p<0.01$. vs. Control + IN-Ins and $\mathrm{STZ}+\mathrm{IN}-\mathrm{Ins}], 20-30 \mu \mathrm{m}\left[\mathrm{F}_{(5517)}=55.54^{* * *} p<0.01\right.$ vs. rest of the groups, $\neq \neq p<0.01$. vs. Control + IN-Ins and STZ + IN-Ins $], 40-50 \mu \mathrm{m}[\mathrm{F}(5529)=47.39,+\dagger p<0.01$ vs. Control, Control + ICV-Ins, Control + IN-Ins, STZ + INIns, 㧊 $p<0.01$. vs. Control + IN-Ins and STZ + IN-Ins], $50-60 \mu \mathrm{m}\left[\mathrm{F}_{(5529)}=47.3958,++p<0.01\right.$ vs. Control, Control + ICV-Ins, Control + IN-Ins, STZ + IN-Ins, 


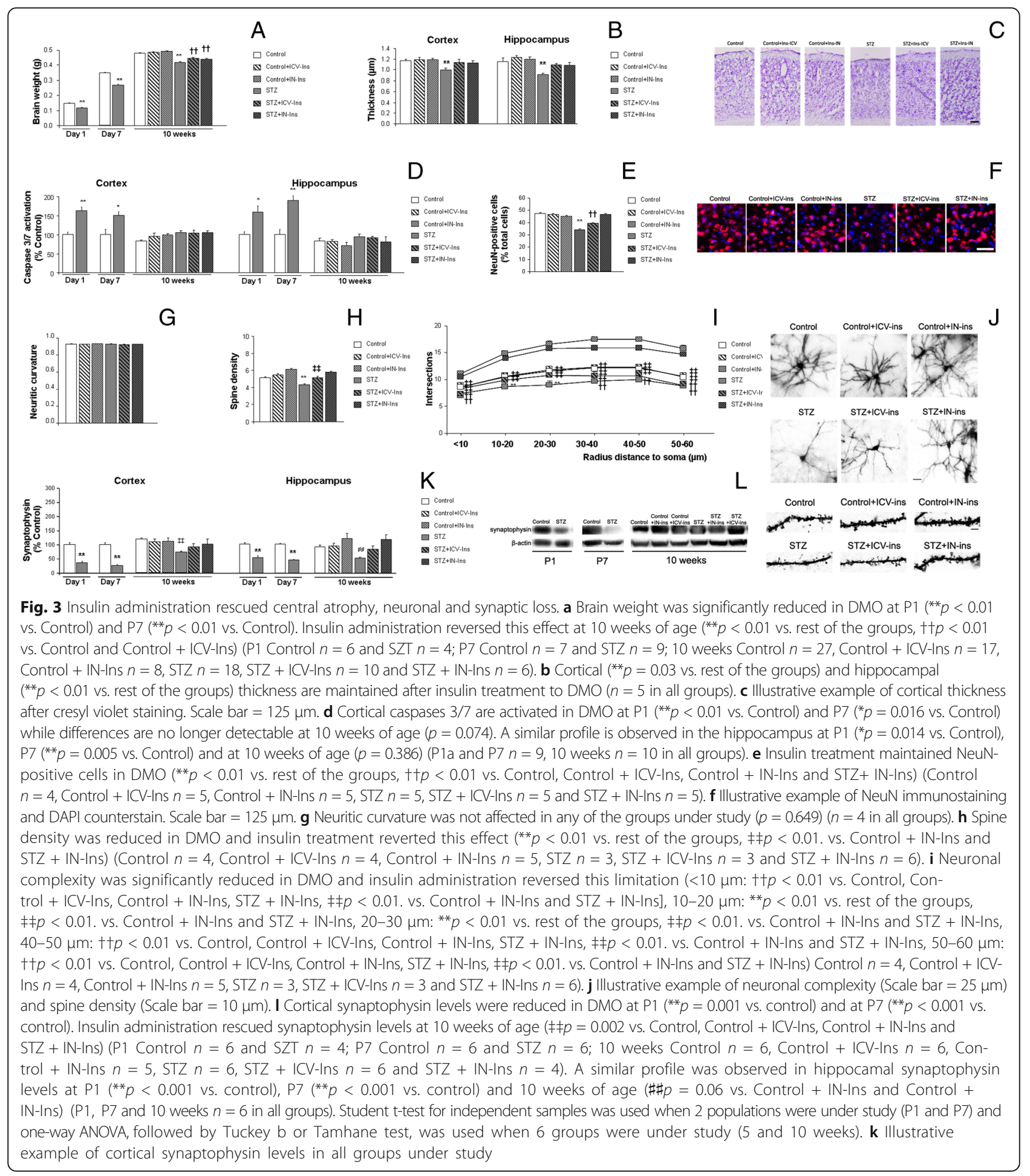

$\neq \neq p<0.01$. vs. Control + IN-Ins and STZ + IN-Ins] (Fig. 3i and j). Synaptophysin was significantly reduced in the cortex from DMO at P1 (** $p=0.001$ vs. Control) and P7 ( ${ }^{* * *} p=0.001$ vs. Control). At 10 weeks ICV insulin treatment improved this effect that reached statistical significance in IN treated animals $\left[\mathrm{F}_{(5,27)}=4.97, \quad \neq \neq p=0.002\right.$ vs. Control, Control + ICV-Ins, Control + IN-Ins and STZ+ IN-Ins] (Fig. 3k and 1). A similar profile was observed in the hippocampus at P1 $\left({ }^{* *} p<0.001\right.$ vs. Control), P7 
(*** $p<0.001$ vs. Control) and 10 weeks of age

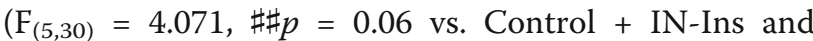
STZ + IN-Ins) (Fig. 3k).

\section{Proliferation and neurogenesis}

In the SVZ the number of BrdU+ cells was significantly compromised in DMO (Fig. 4a and d) and a complete recovery was observed after insulin treatment $\left[\mathrm{F}_{(5,78)}=3.5,{ }^{* *} p=0.07\right.$ vs. rest of the groups]. DCX burden was also reduced DMO and ICV insulin treatment reversed this situation $\left[\mathrm{F}_{(5,74)}=2.91,+p=0.019\right.$ vs. Control, Control + IN-Ins, Control + ICV-Ins and STZ + ICV-Ins] (Fig. 4a and d). BrdU+ cells were significantly reduced in the cortex from DMO. This situation improved by ICV-Ins administration and completely recovered after IN-Ins $\left[\mathrm{F}_{(5208)}=7.87, \# \# p<0.01\right.$ vs. Control + IN-Ins and STZ + IN-Ins]. A similar profile was observed when we quantified DCX-positive cells, although differences did not reach statistical significance $\left(\left[\mathrm{F}_{(5208)}=0.4, p=0.848\right]\right)$ (Fig. 4b). A similar profile was observed in the hippocampus for BrdU-positive cells
$\left[\mathrm{F}_{(5118)}=2.59 \# p<0.05\right.$ vs. STZ + IN-Ins $]$ and. DCXpositive cells $\left(\left[\mathrm{F}_{(5122)}=0.195, p=0.964\right]\right)$ (Fig. 4c).

\section{Akt levels}

Phopho-Akt/total Akt levels were reduced in the cortex of DMO at P1 ${ }^{* *} p=0.001$ vs. Control) and P7 $(* * p<0.001$ vs. Control). By 10 weeks of age, phospho-Akt levels were still reduced in DMO and insulin administration slightly increased the ratio, although differences were not statistically significant $\left[\mathrm{F}_{(5,29)}=2.34, p=0.066\right]$ (Fig. 5a and b). A similar profile was observed in the hippocampus at P1 ${ }^{* * *} p<0.01$ vs. Control), P7 ${ }^{* * *} p<0.01$ vs. Control) and by 10 weeks of age $\left[\mathrm{F}_{(5,30)}=1.98, p=0.390\right]$ (Fig. 5a). Since it is feasible that the time selected after insulin delivery might be too long we also measured Phopho-Akt/total Akt ratio 4h after ICV or intranasal administration. Phospho-Akt/total Akt ratios were significantly increased in those regions located in the proximity of the administration site: the hippocampus and the striatum after ICV administration

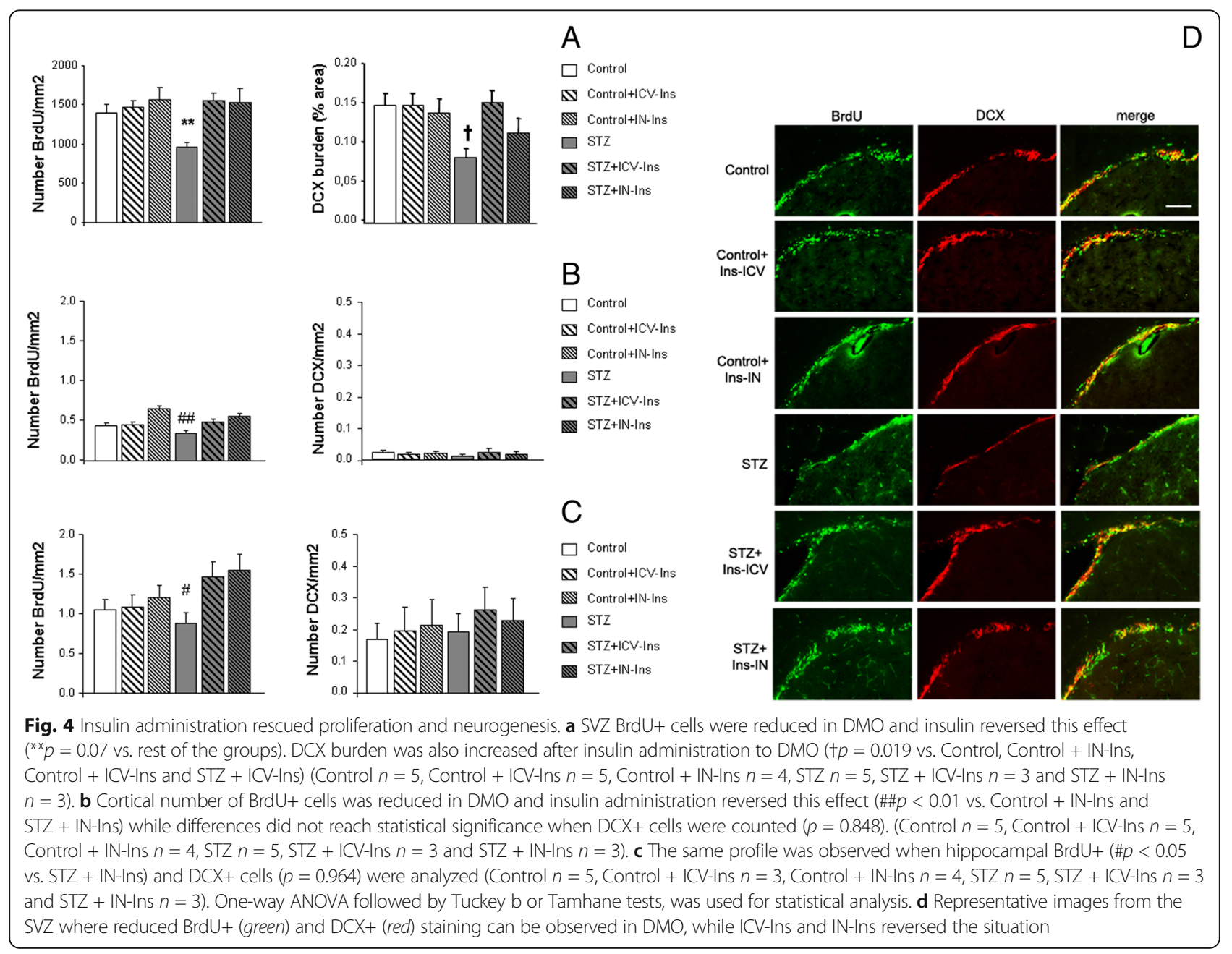




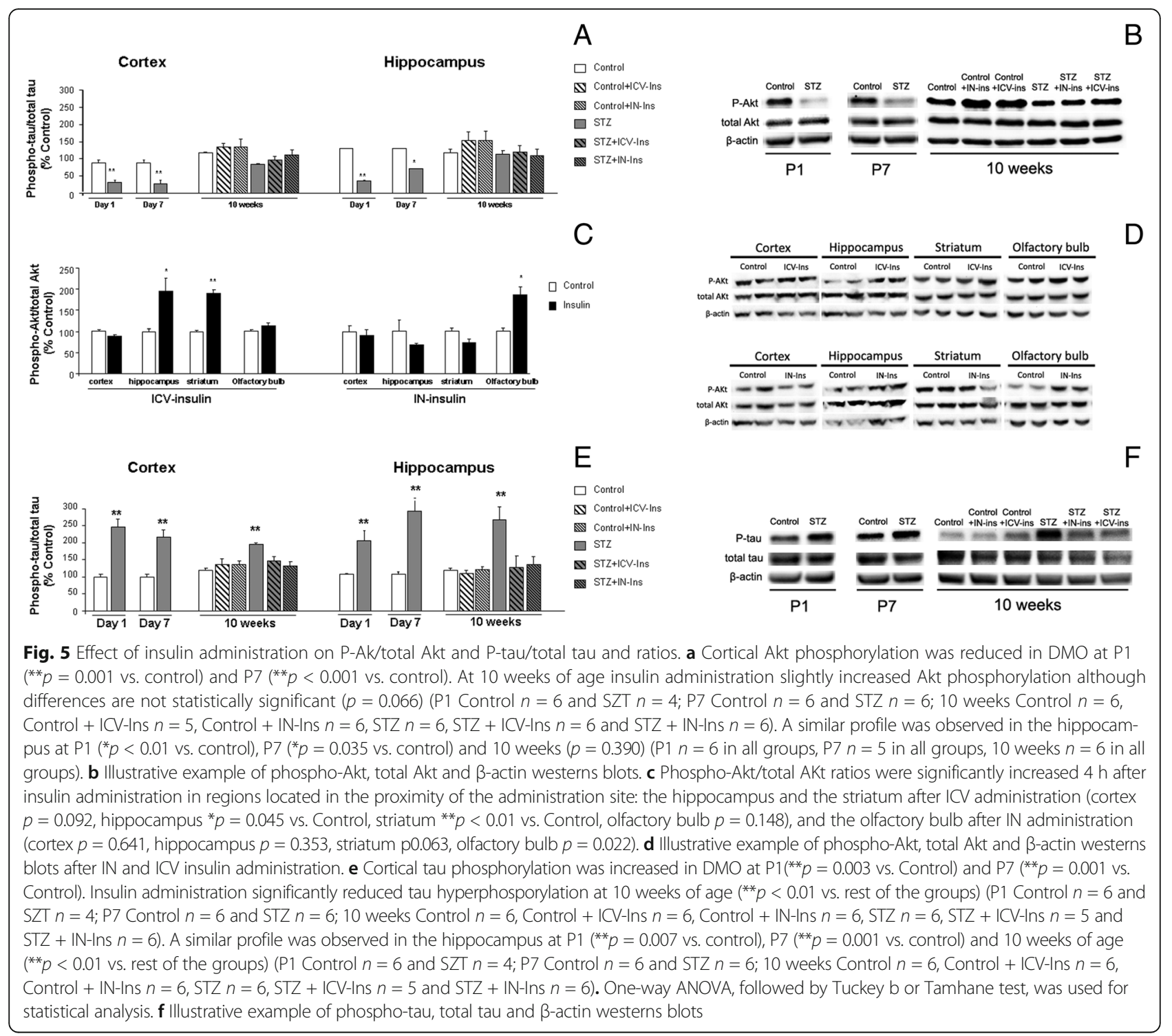

(cortex $p=0.092$, hippocampus $" p=0.045$ vs. Control, striatum ${ }^{* *} p<0.01$ vs. Control, olfactory bulb $p=0.148$ ), and the olfactory bulb after intranasal administration (cortex $p=0.641$, hippocampus $p=0.353$, striatum $p=0.063$, olfactory bulb $* p=0.022$ ) (Fig. $5 \mathrm{c}$ and d).

\section{Tau pathology}

Tau phosphorylation was significantly increased in $\mathrm{DMO}$ at P1 $\left({ }^{* * *} p=0.03\right.$ vs. Control $)$ and P7 $(* * p<0.01$ vs. Control). This effect was still detectable after 10 weeks, and it was completely reversed by insulin administration $\left[\mathrm{F}_{(5,29)}=5.25\right.$, $" p<0.01$ vs. rest of the groups] (Fig. 5e and f). A similar profile was observed in the hippocampus (P1, $* * p=0.007$ vs. Control; P7, $* * p<0.001$ vs. Control and 10 weeks of age $\left[\mathrm{F}_{(5,29)}=6.68,{ }^{* * *} p<0.01\right.$ vs. rest of the groups] (Fig. 5e).

\section{Spontaneous bleeding}

Cortical haemorrhage burden in DMO at P7 (** $p<0.01$ vs. Control) and density (** $p<0.01$ vs. Control) were increased, without affecting individual haemorrhage size $(p=0.053)$ (Fig. 6a). By 10 weeks of age haemorrhage burden was significantly higher in DMO and insulin administration significantly reduced this effect $\left[\mathrm{F}_{(5153)}=16.052,{ }^{* * *} p<0.01\right.$ vs. 0.01 vs. rest of the groups, $++p<0.01$ vs. Control, Control + ICV-Ins, Control + IN-Ins, $\neq \neq p<0.01$ vs. Control], by reducing haemorrhage density (number haemorrhages $/ \mathrm{mm}^{2}$ ) $\left[\mathrm{F}_{(5163)}=15.54,{ }^{* *} p<0.01\right.$ vs. 0.01 vs. rest of the groups, $\neq \neq p<0.01$ vs. Control] whereas haemorrhage size was not affected $\left[\mathrm{F}_{(5943)}=4.12, p=0.01\right.$ and no further differences were detected by Tuckey b test] (Fig. 6a and b). A similar profile was observed in the hippocampus when we analyzed haemorrhage burden ${ }^{* * *} p=0.005$ vs. 


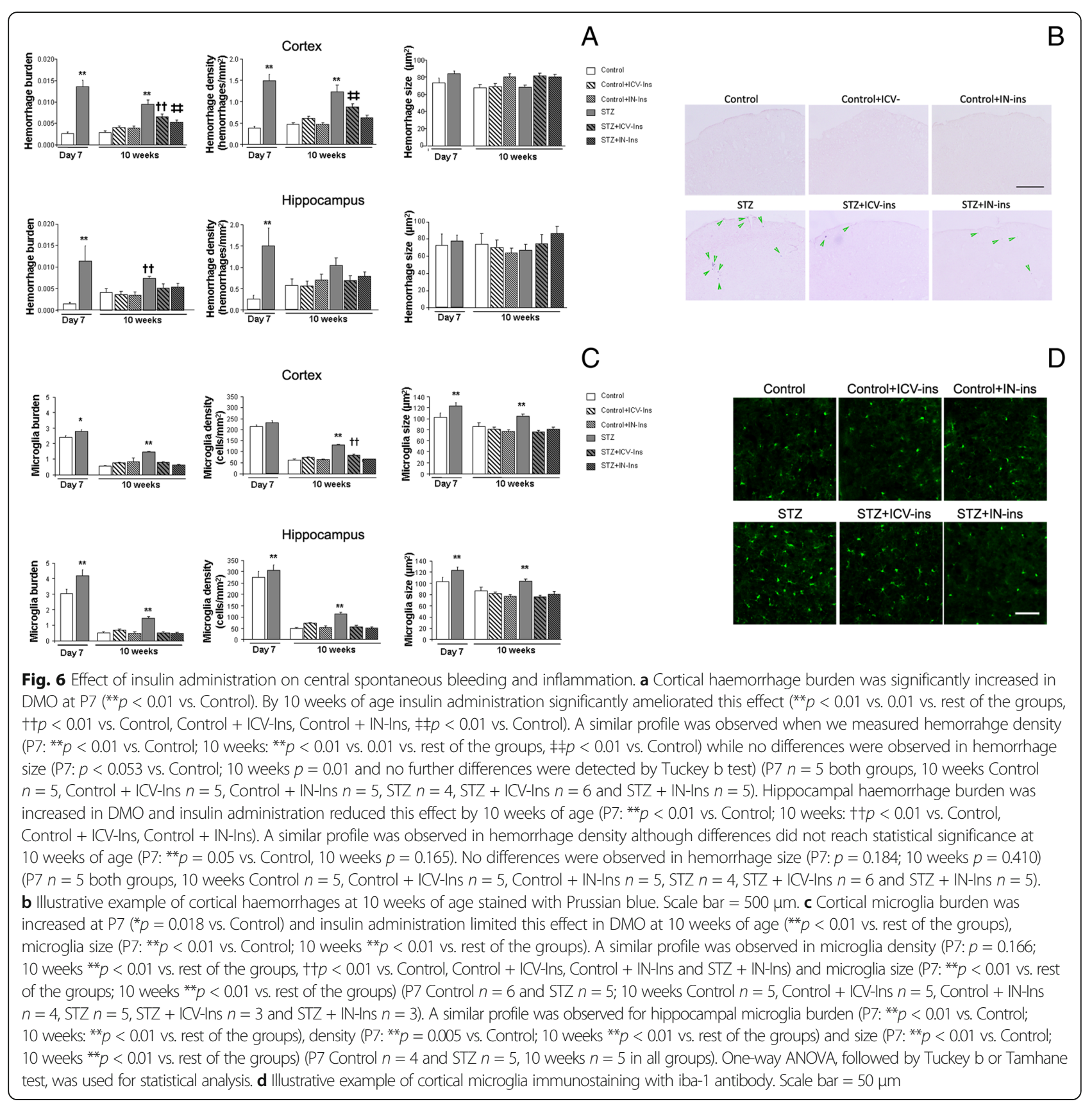

Control), haemorrhage density $(* * p=0.005$ vs. Control) and haemorrhage size $(p=0.184)$ at P7 (Fig. 6a) or at 10 weeks of age, (burden: $\left[\mathrm{F}_{(5,61)}=16.052,++p<0.01\right.$ vs. Control, Control + ICV-Ins, Control + IN-Ins], density: $\left[\mathrm{F}_{(5,68)}=1.62, p=0.165\right]$ and size $\left[\mathrm{F}_{(5119)}=1.01\right.$, $p=0.410]$ ) (Fig. 6a).

\section{Inflammation}

At P7 microglia burden (" $p=0.018$ vs. Control) and microglia size $(* * p<0.01$ vs. Control) were increased in the cortex. Microglia density was not affected $(p=0.166)$ (Fig. 6c). By 10 weeks of age, increased inflammation in DMO was completely reversed by insulin administration $\left[\mathrm{F}_{(5,3437)}=155.16,{ }^{* * *} p<0.01\right.$ vs. rest of the groups, $++p<0.01$ vs. Control, Control + IN-Ins and STZ + IN-Ins]. Microglia density $\left[\mathrm{F}_{(5,3429)}=92 \cdot 12\right.$, *** $p<0.01$ vs. rest of the groups, $+\dagger p<0.01$ vs. Control, Control + IN-Ins, Control + ICV-Ins and STZ + IN-Ins] and microglia size $\left[\mathrm{F}(5,3665)=28.91,{ }^{* *} p<0.01\right.$ vs. rest of the groups] were also reduced (Fig. $6 \mathrm{c}$ and d). A similar profile was observed in the hippocampus at P7 (microglia burden: ${ }^{* * *} p<0.01$ vs. Control, size ${ }^{* * *} p<0.01$ vs. Control and number: $* 0<0.01$ vs. Control) (Fig. 6c) and at 10 weeks of age (burden: $\left[\mathrm{F}_{(5537)}=31.79,{ }^{* *} p<0.01\right.$ vs. 
rest of the groups], density: $\left[\mathrm{F}_{(5535)}=16.10,{ }^{* *} p<0.01 \mathrm{vs}\right.$. rest of the groups] and size: $\left[\mathrm{F}_{(5480)}=8.67, * * p<0.01 \mathrm{vs}\right.$. rest of the groups]) (Fig. 6c).

\section{Discussion}

Increased risk of metabolic and cardiovascular diseases in DMO have been reported in animal and human [24] studies. While cognitive alterations in DMO have also been observed $[9,10]$, it is noteworthy that most of previous studies are based on observational cohorts. Therefore a direct causal influence of intrauterine hyperglycemia remains uncertain [25] and therapeutic options have not been completely addressed. To help elucidate some of these aspects, we have analyzed the short and long-term central complications in a murine model of DMO, as well as the effects of ICV and non-invasive IN insulin treatments. Our approach included administering STZ to mothers before crossing [26], and central complications in DMO have been also observed when mothers are mated and diabetes is induced immediately afterwards [27]. However we cannot exclude that final outcomes might be slightly different depending on the protocol used, time selected to induce diabetes or endpoints under study.

The fact that glucose levels recovered 7 days after birth might be due to regularization of basal levels once the pups are no longer in intrauterine environment. Increased insulin levels did not reach statistical significance, however it remains feasible that the slight a hyperglycemic increase observed might be enough to control glycaemia in our population. In DMO we also observed growth inhibition, impaired GTT and insulin response, as previously reported in DMO, that show decreased insulin sensitivity and low insulin secretion [28]. The fact that DMO do not regularly release insulin in the GTT suggests a pancreatic exhaustion, over insulin resistance. Nevertheless, we cannot unequivocally point towards a single cause leading to observed metabolic alterations. On the other hand, central insulin administration reversed all these effects, supporting the role of insulin in the regulation of peripheral metabolic complications [29, 30].

Central pathology in young adults from diabetic mothers revealed the long term effects of severe maternal hyperglycemia in learning and memory. Epidemiological studies have shown that maternal diabetes is negatively associated with offspring's cognitive development [10] and gestational diabetes has been related to lower general intelligence, language impairment, attention weakness, impulsivity or behavioural problems (for review [9]). A few studies have assessed the ongterm effects of maternal diabetes in the descendants [31] and to our knowledge this is the first one trying to reverse observed deficits by administering insulin to the offspring. Spatial and episodic memory impairment in
DMO improved after ICV insulin administration, and were completely reversed after IN insulin. While ICV administration provides useful tool to guarantee access to the CNS in animal models [30], its translational approach is not feasible. On the other hand, IN insulin uses a transport system, via the nasal epithelium into the brain, that avoids high levels of insulin in the periphery. Moreover, previous studies with IN insulin support that insulin signal is crucial in neuronal function and cognition, improving cognitive function in healthy subjects [32], diabetic patients [33] and murine models [34], however to our knowledge no previous studies have tested insulin administration to restore cognitive deficits associated to intrauterine hyperglycaemia.

Significant brain atrophy was observed in DMO up to early adulthood, associated with increased caspase activity, cortical and hippocampal thinning, in line with previous studies [35]. Likewise, NeuN/DAPI ratios were reduced in DMO, while insulin treatment completely reversed these observations. In order to further characterize brain atrophy, we examined neuronal morphology, since it has been shown to correlate with neuronal function [36]. Neurite curvature was not significantly altered in DMO, however, severe reduction of neuronal ramifications, spine density and synaptophysin levels were observed, in accordance with previous studies [37]. Synaptogenesis is a relevant event during development that requires a fine and precise pre- and postsynaptic specialization [35]. Therefore, interferences at this level may result in abnormal layer development and related cognition and behavioural problems. Insulin treatment fully recovered neuronal complexity and spine density in DMO, in line with previous studies showing that altered maternal metabolism may impair offspring neuronal projections normal development [38]. It has been already reported that foetal hyperglycaemia alters the expression of genes involved in proliferation and differentiation of neural cells [35]. Insulin also plays a crucial role in proliferation and neurogenesis in the CNS and in our hands, DMO presented a significant reduction of both processes, especially relevant in a neurogenic niche as the SVZ. Insulin signaling in the brain can respond to changes in systemic metabolic state while local insulin signaling promotes neurogenesis [39], as observed in our DMO after insulin treatment. Since Akt plays a crucial role in insulin signaling, as well as in cell proliferation and cell survival, it has been previously suggested that variations in Akt may underlie the observed alterations in DMO [40]. We also observed a reduction in phospho-Akt levels in young DMO, supporting that diabetes during pregnancy strongly influences the regulation of Akt in the developing brain, and that strict maternal metabolic control might be crucial [26]. Insulin 
treatment slightly increased phospho-Akt levels. Limited differences observed might be due to the fact that determinations were performed days and weeks after insulin administration. Therefore, we also performed determinations $4 \mathrm{~h}$ after insulin administration and we detected that phospho-Akt/total AKt ratios were significantly increased in those regions located in the proximity of the administration site: the hippocampus and the striatum after ICV administration, and the olfactory bulb after intranasal administration, in line with previous observations [41].

Tau hyperphosphorylation exerts toxic effects and it is a pathological hallmark of neurodegenerative disorders, also described in different diabetic animal models $[17,19]$. It has been suggested that hyperglycaemic conditions induce tau deregulation [42]. We observed a significant increase of hyperphophorylated tau in DMO and similar outcomes have been observed in other models [43]. However, to our knowledge, the detected improvement after insulin treatment has not been previously reported.

Small vessel disease is a more common cause of ischemic stroke in people with diabetes [44]. It has been also described that embryos from diabetic mothers present generalized vascular lesions [45], however we believe no previous studies have assessed spontaneous central bleeding in DMO. Haemorrhage burden was increased in P7 DMO, and this effect was still detectable in the adulthood, supporting the long-term effects of maternal diabetes in the offspring. Previous studies have also associated the presence of haemorrhages with an increase in tau phosphorylation [46, 47]. Moreover, insulin treatment can effectively reverse these effects. We also detected a significant increase in microglia burden up to early adulthood in DMO, in line with previous studies showing that maternal prediabetes is enough to increase microglia activation and cytokines involved with trafficking across the blood-brain barrier [48], suggesting an activation of the local inflammatory response that may ultimately contribute to observed spontaneous bleeding. Furthermore, insulin treatment reduced microglia activation, supporting its role as an anti-inflammatory agent (for review see [49]).

\section{Conclusions}

These data suggest that maternal diabetes not only affects the CNS development but it also has long-term effects, that are still evident in the adulthood. Maternal diabetes affects neuronal complexity and synaptic density, tau hyperphosphorylation, central inflammation or spontaneous bleeding, which may altogether compromise learning and memory abilities. Moreover, ICV insulin administration counterbalances many of these aspects and non-invasive IN administration robustly reverses detected alterations. This could lead to studies in greater depth on the use of IN insulin as a therapeutic alternative for those infants from diabetic mothers, who may benefit from more exhaustive follow-up assessments [9] and individualized treatments.

\section{Abbreviations}

BrdU: 5-bromo-3-deoxyuridine; CNS: Central nervous system;

DCX: doublecortin; DMO: diabetic mothers offspring; GT: glucose tolerance test; ICV: intracerebroventricular; ICV-Ins: Intracerebroventricular insulin; IN: intranasal; IN-Ins: Intranasal insulin; MWM: Morris water maze; NOD: new object discrimination; STZ: streptozotozin; SVZ: subventricular zone

\section{Acknowledgements}

We thank the animal facility (SEPA) of the University of Cadiz for their support and Consuelo Rivera Sanchez and Miguel Angel Rodriguez Gomez for their technical support (University of Cadiz).

\section{Funding}

Fundacion Eugenio Rodríguez Pascual (2015). Proyectos de Excelencia, Consejería de Economía, Innovación, Ciencia y Empleo Junta de Andalucía (P11-CTS-7847), ISCIII-Subdirección General de Evaluación y Fomento de la Investigación and cofinanced by the European Union (Fondo Europeo de Desarrollo Regional, FEDER) "Una manera de hacer Europa" (PI12/00675). Programa Estatal de Promoción del Talento y su Empleabilidad en I+D+i, Subprograma Estatal de Movilidad, del Plan Estatal de Investigación Científica y Técnica y de Innovación 2013-2016 (PRX16/00246). Programa Estatal de Investigación, Desarrollo e Innovación Orientada a los Retos de la Sociedad. Ministerio de Economía y Competitividad (BFU2016-75038-R). Gobierno de España. (Monica Garcia-Alloza).

Availability of data and materials

Data could be accessed on request.

\section{Authors' contributions}

JJR-R conceived and performed the experiments, DS-S, AD-M and Cl-G performed and analyzed the experiments, SL-L analyzed and reviewed the manuscript, MGA conceived and analyzed the experiments, and wrote the manuscript approved by all authors.

\section{Ethics approval}

All experimental procedures were approved by Junta de Andalucia, (Guidelines for Care and Use of Experimental Animals, European Commission Directive 2010/63/UE and Spanish Royal Decree 53/2013) and the University of Cadiz Bioethical Committee.

\section{Consent for publication}

All authors have reviewed the manuscript and consented the publication.

Competing interests

The authors declare that they have no competing interests.

\section{Publisher's Note}

Springer Nature remains neutral with regard to jurisdictional claims in published maps and institutional affiliations.

\section{Author details}

${ }^{1}$ Division of Physiology, School of Medicine Universidad de Cadiz, Plaza Fragela sn, 4 piso 410, Cadiz, Spain. ${ }^{2}$ Instituto de Investigación Biomédica e Innovación en Ciencias Biomédicas de la Provincia de Cádiz (INiBICA), Cadiz, Spain. ${ }^{3}$ Division of Neonatology, Hospital Universitario Puerta del Mar, Cadiz, Spain. ${ }^{4}$ Division of Pediatrics, Hospital Universitario Puerta del Mar, Cadiz, Spain.

Received: 17 January 2017 Accepted: 24 July 2017

Published online: 02 August 2017

\section{References}

1. Anna V, van der Ploeg HP, Cheung NW, Huxley RR, Bauman AE. Sociodemographic correlates of the increasing trend in prevalence of gestational diabetes mellitus in a large population of women between 1995 and 2005. Diabetes Care. 2008;31:2288-93. 
2. Metzger BE, Lowe LP, Dyer AR, Trimble ER, Chaovarindr U, Coustan DR, Hadden DR, McCance DR, Hod M, McIntyre HD, Oats JJ, Persson B, Rogers MS, Sacks DA. Hyperglycemia and adverse pregnancy outcomes. N Engl J Med. 2008;358:1991-2002.

3. McCance DR. Diabetes in pregnancy. Best Pract Res Clin Obstet Gynaecol. 2015;29:685-99.

4. Silverman BL, Metzger BE, Cho NH, Loeb CA. Impaired glucose tolerance in adolescent offspring of diabetic mothers. Relationship to fetal hyperinsulinism. Diabetes Care. 1995;18:611-7.

5. Piya MK, Harte AL, Sivakumar K, Tripathi G, Voyias PD, James S, Sabico S, Al-Daghri NM, Saravanan P, Barber TM, Kumar S, Vatish M, McTernan PG. The identification of irisin in human cerebrospinal fluid: influence of adiposity, metabolic markers, and gestational diabetes. Am J Physiol Endocrinol Metab. 2014;306:E512-8.

6. Steculorum SM, Bouret SG. Maternal diabetes compromises the organization of hypothalamic feeding circuits and impairs leptin sensitivity in offspring. Endocrinology. 2011;152:4171-9.

7. Dheen ST, Tay SS, Boran J, Ting LW, Kumar SD, Fu J, Ling EA. Recent studies on neural tube defects in embryos of diabetic pregnancy: an overview. Curr Med Chem. 2009;16:2345-54.

8. Hami J, Vafaei-Nezhad S, Ghaemi K, Sadeghi A, Ivar G, Shojae F, Hosseini M. Stereological study of the effects of maternal diabetes on cerebellar cortex development in rat. Metab Brain Dis. 2016;31:643-52.

9. Perna R, Loughan AR, Le J, Tyson K. Gestational Diabetes: Long-Term Central Nervous System Developmental and Cognitive Sequelae. Appl Neuropsychol Child. 2015;4:217-20.

10. Adane AA, Mishra GD, Tooth LR. Diabetes in Pregnancy and Childhood Cognitive Development: A Systematic Review. Pediatrics. 2016;137(5) doi:10. 1542/peds.2015-4234.

11. Aggarwal A, Khera A, Singh I, Sandhir R. S-nitrosoglutathione prevents bloodbrain barrier disruption associated with increased matrix metalloproteinase- 9 activity in experimental diabetes. J Neurochem. 2015;132:595-608.

12. Macedo RF, Furlan FC, Marshall PS, Michelotto JB, Gontijo JA. Effect of intracerebroventricularly injected insulin on urinary sodium excretion by cerebroventricular streptozotocin-treated rats. Braz J Med Biol Res. 2003;36:1193-9.

13. Koch C, Augustine RA, Steger J, Ganjam GK, Benzler J, Pracht C, Lowe C, Schwartz MW, Shepherd PR, Anderson GM, Grattan DR, Tups A. Leptin rapidly improves glucose homeostasis in obese mice by increasing hypothalamic insulin sensitivity. J Neurosci. 2010;30:16180-7.

14. Renner DB, Svitak AL, Gallus NJ, Ericson ME, Frey WH 2nd, Hanson LR. Intranasal delivery of insulin via the olfactory nerve pathway. J Pharm Pharmacol. 2012;64:1709-14.

15. Marks DR, Tucker K, Cavallin MA, Mast TG, Fadool DA. Awake intranasal insulin delivery modifies protein complexes and alters memory, anxiety, and olfactory behaviors. J Neurosci. 2009;29:6734-51.

16. Jimenez-Palomares M, Ramos-Rodriguez JJ, Lopez-Acosta JF, Pacheco-Herrero M, Lechuga-Sancho AM, Perdomo G, Garcia-Alloza M, Cozar-Castellano I. Increased Abeta production prompts the onset of glucose intolerance and insulin resistance. Am J Physiol Endocrinol Metab. 2012;302:E1373-80.

17. Ramos-Rodriguez JJ, Ortiz O, Jimenez-Palomares M, Kay KR, Berrocoso E, Murillo-Carretero MI, Perdomo G, Spires-Jones T, Cozar-Castellano I, LechugaSancho AM, Garcia-Alloza M. Differential central pathology and cognitive impairment in pre-diabetic and diabetic mice. Psychoneuroendocrinology. 2013:38:2462-75

18. Ramos-Rodriguez JJ, Molina-Gil S, Ortiz-Barajas O, Jimenez-Palomares M, Perdomo G, Cozar-Castellano I, Lechuga-Sancho AM, Garcia-Alloza M. Central proliferation and neurogenesis is impaired in type 2 diabetes and prediabetes animal models. PLoS One. 2014;9:e89229.

19. Ramos-Rodriguez JJ, Infante-Garcia C, Galindo-Gonzalez L, Garcia-Molina Y, Lechuga-Sancho A, Garcia-Alloza M. Increased Spontaneous Central Bleeding and Cognition Impairment in APP/PS1 Mice with Poorly Controlled Diabetes Mellitus. Mol Neurobiol. 2016;53:2685-97.

20. Infante-Garcia C, Ramos-Rodriguez JJ, Galindo-Gonzalez L, Garcia-Alloza M. Longterm central pathology and cognitive impairment are exacerbated in a mixed model of Alzheimer's disease and type 2 diabetes. Psychoneuroendocrinology. 2015;65:15-25.

21. Ramos-Rodriguez JJ, Spires-Jones T, Pooler AM, Lechuga-Sancho AM, Bacskai BJ, Garcia-Alloza M. Progressive Neuronal Pathology and Synaptic Loss Induced by Prediabetes and Type 2 Diabetes in a Mouse Model of Alzheimer's Disease. Mol Neurobiol. 2016: in press.
22. Garcia-Alloza M, Borrelli LA, Rozkalne A, Hyman BT, Bacskai BJ. Curcumin labels amyloid pathology in vivo, disrupts existing plaques, and partially restores distorted neurites in an Alzheimer mouse model. J Neurochem. 2007;102:1095-104.

23. Ramos-Rodriguez JJ, Jimenez-Palomares M, Murillo-Carretero MI, Infante-Garcia C, Berrocoso E, Hernandez-Pacho F, Lechuga-Sancho AM, Cozar-Castellano I, Garcia-Alloza M. Central vascular disease and exacerbated pathology in a mixed model of type 2 diabetes and Alzheimer's disease. Psychoneuroendocrinology. 2015:62:69-79.

24. Fraser A, Lawlor DA. Long-term health outcomes in offspring born to women with diabetes in pregnancy. Curr Diab Rep. 2014;14:489.

25. Camprubi Robles M, Campoy C, Garcia Fernandez L, Lopez-Pedrosa JM, Rueda R, Martin MJ. Maternal Diabetes and Cognitive Performance in the Offspring: A Systematic Review and Meta-Analysis. PLoS One. 2015;10:e0142583.

26. Hami J, Kerachian MA, Karimi R, Haghir H, Sadr-Nabavi A. Effects of streptozotocin-induced type 1 maternal diabetes on PI3K/AKT signaling pathway in the hippocampus of rat neonates. J Recept Signal Transduct Res. 2016;36:254-60.

27. Sandeep MS, Nandini CD. Brain heparan sulphate proteoglycans are altered in developing foetus when exposed to in-utero hyperglycaemia. Metab Brain Dis. 2017.

28. Blondeau B, Joly B, Perret C, Prince S, Bruneval P, Lelievre-Pegorier M, Fassot C, Duong Van Huyen JP. Exposure in utero to maternal diabetes leads to glucose intolerance and high blood pressure with no major effects on lipid metabolism. Diabetes Metab. 2011;37:245-51.

29. Heni M, Wagner R, Kullmann S, Veit R, Mat Husin H, Linder K, Benkendorff C, Peter A, Stefan N, Haring HU, Preissl H, Fritsche A. Central insulin administration improves whole-body insulin sensitivity via hypothalamus and parasympathetic outputs in men. Diabetes. 2014;63:4083-8.

30. Ott V, Benedict C, Schultes B, Born J, Hallschmid M. Intranasal administration of insulin to the brain impacts cognitive function and peripheral metabolism. Diabetes Obes Metab. 2012;14:214-21.

31. Chandna AR, Kuhlmann N, Bryce CA, Greba Q, Campanucci VA, Howland JG. Chronic maternal hyperglycemia induced during mid-pregnancy in rats increases RAGE expression, augments hippocampal excitability, and alters behavior of the offspring. Neuroscience. 2015:303:241-60.

32. Holscher C. First clinical data of the neuroprotective effects of nasal insulin application in patients with Alzheimer's disease. Alzheimers Dement. 2014;10:S33-7.

33. Novak V, Milberg W, Hao Y, Munshi M, Novak P, Galica A, Manor B, Roberson P, Craft S, Abduljalil A. Enhancement of vasoreactivity and cognition by intranasal insulin in type 2 diabetes. Diabetes Care. 2014;37:751-9.

34. Francis GJ, Martinez JA, Liu WQ, Xu K, Ayer A, Fine J, Tuor UI, Glazner G, Hanson LR, Frey WH 2nd, Toth C. Intranasal insulin prevents cognitive decline, cerebral atrophy and white matter changes in murine type I diabetic encephalopathy. Brain. 2008;131:3311-34.

35. Hami J, Sadr-Nabavi A, Sankian M, Balali-Mood M, Haghir H. The effects of maternal diabetes on expression of insulin-like growth factor-1 and insulin receptors in male developing rat hippocampus. Brain Struct Funct. 2013;218:73-84.

36. Stern EA, Bacskai BJ, Hickey GA, Attenello FJ, Lombardo JA, Hyman BT. Cortical synaptic integration in vivo is disrupted by amyloid-beta plaques. J Neurosci. 2004;24(19):4535-40.

37. Vafaei-Nezhad S, Hami J, Sadeghi A, Ghaemi K, Hosseini M, Abedini MR, Haghir $\mathrm{H}$. The impacts of diabetes in pregnancy on hippocampal synaptogenesis in rat neonates. Neuroscience. 2016:318:122-33.

38. Vogt MC, Paeger L, Hess S, Steculorum SM, Awazawa M, Hampel B, Neupert S, Nicholls HT, Mauer J, Hausen AC, Predel R, Kloppenburg P, Horvath TL, Bruning JC. Neonatal insulin action impairs hypothalamic neurocircuit formation in response to maternal high-fat feeding. Cell. 2014;156:495-509.

39. Liu J, Speder P, Brand AH. Control of brain development and homeostasis by local and systemic insulin signalling. Diabetes Obes Metab. 2014; 16(Suppl 1):16-20.

40. Kruse MS, Barutta J, Vega MC, Coirini H. Down regulation of the proliferation and apoptotic pathways in the embryonic brain of diabetic rats. Cell Mol Neurobiol. 2012;32:1031-7

41. Bell GA, Fadool DA. Awake, long-term intranasal insulin treatment does not affect object memory, odor discrimination, or reversal learning in mice. Physiol Behav. 2017:174:104-13.

42. Kim B, Backus C, Oh S, Hayes JM, Feldman EL. Increased tau phosphorylation and cleavage in mouse models of type 1 and type 2 diabetes. Endocrinology. 2009;150:5294-301. 
43. Martin SA, Jameson CH, Allan SM, Lawrence CB. Maternal high-fat diet worsens memory deficits in the triple-transgenic (3xTgAD) mouse model of Alzheimer's disease. PLoS One. 2014;9:e99226.

44. Hankey GJ, Anderson NE, Ting RD, Veillard AS, Romo M, Wosik M, Sullivan DR, O'Connell RL, Hunt D, Keech AC. Rates and predictors of risk of stroke and its subtypes in diabetes: a prospective observational study. J Neurol Neurosurg Psychiatry. 2013;84:281-7.

45. Zabrodina W, Shreder ED, Shreder OV, Durnev AD, Seredenin SB. Impaired prenatal development and glycemic status in the offspring of rats with experimental streptozotocin-induced diabetes and their correction with afobazole. Bull Exp Biol Med. 2014;158:16-20.

46. Wen Y, Yang S, Liu R, Brun-Zinkernagel AM, Koulen P, Simpkins JW. Transient cerebral ischemia induces aberrant neuronal cell cycle re-entry and Alzheimer's disease-like tauopathy in female rats. J Biol Chem. 2004;279:22684-92.

47. Zhang Q, Gao T, Luo Y, Chen X, Gao G, Gao X, Zhou Y, Dai J. Transient focal cerebral ischemia/reperfusion induces early and chronic axonal changes in rats: its importance for the risk of Alzheimer's disease. PLoS One. 2012;7:e33722.

48. Grayson BE, Levasseur PR, Williams SM, Smith MS, Marks DL, Grove KL. Changes in melanocortin expression and inflammatory pathways in fetal offspring of nonhuman primates fed a high-fat diet. Endocrinology. 2010;151:1622-32.

49. Sun Q, Li J, Gao F. New insights into insulin: The anti-inflammatory effect and its clinical relevance. World J Diabetes. 2014:5:89-96.

Submit your next manuscript to BioMed Central and we will help you at every step:

- We accept pre-submission inquiries

- Our selector tool helps you to find the most relevant journal

- We provide round the clock customer support

- Convenient online submission

- Thorough peer review

- Inclusion in PubMed and all major indexing services

- Maximum visibility for your research

Submit your manuscript at www.biomedcentral.com/submit
Biomed Central 